\title{
BMJ Open Evaluating quality of overall care among older adults with diabetes with comorbidities in Ontario, Canada: a retrospective cohort study
}

\author{
Yelena Petrosyan (D , ${ }^{1}$ Kerry Kuluski, ${ }^{2,3}$ Jan Barnsley, ${ }^{2}$ Barbara Liu, ${ }^{4}$ \\ Walter P Wodchis (D) ${ }^{2,3}$
}

To cite: Petrosyan Y, Kuluski K, Barnsley J, et al. Evaluating quality of overall care among older adults with diabetes with comorbidities in Ontario, Canada: a retrospective cohort study. BMJ Open 2020;10:e033291. doi:10.1136/ bmjopen-2019-033291

- Prepublication history and additional material for this paper are available online. To view these files, please visit the journal online (http://dx.doi org/10.1136/bmjopen-2019033291).

Received 31 July 2019 Revised 20 December 2019 Accepted 13 January 2020

Check for updates

(C) Author(s) (or their employer(s)) 2020. Re-use permitted under CC BY-NC. No commercial re-use. See rights and permissions. Published by BMJ.

${ }^{1}$ Department of Clinical Epidemiology, Ottawa Hospital Research Institute, Ottawa, Ontario, Canada

${ }^{2}$ Institute of Health Policy, Management and Evaluation, University of Toronto, Toronto, Ontario, Canada

${ }^{3}$ Institute for Better Health, Trillium Health Partners, Toronto, Ontario, Canada

${ }^{4}$ Division of Geriatric Medicine, Department of Medicine, University of Toronto, Toronto, Ontario, Canada

Correspondence to Dr Walter P Wodchis; walter.wodchis@utoronto.ca

\section{ABSTRACT}

Objectives This study aimed to: (1) explore whether the quality of overall care for older people with diabetes is differentially affected by types and number of comorbid conditions and (2) examine the association between process of care measures and the likelihood of all-cause hospitalisations.

Design A population-based, retrospective cohort study. Setting The province of Ontario, Canada.

Participants We identified 673197 Ontarians aged 65 years and older who had diabetes comorbid with hypertension, chronic ischaemic heart disease, osteoarthritis or depression on 1 April 2010.

Main outcome measures The study outcome was the likelihood of having at least one hospital admission in each year, during the study period, from 1 April 2010 to 3 March 2014. Process of care measures specific to older adults with diabetes and these comorbidities, developed by means of a Delphi panel, were used to assess the quality of care. A generalised estimating equations approach was used to examine associations between the process of care measures and the likelihood of hospitalisations.

Results The study findings suggest that patients are at risk of suboptimal care with each additional comorbid condition, while the incidence of hospitalisations and number of prescribed drugs markedly increased in patients with 2 versus 1 selected comorbid condition, especially in those with discordant comorbidities. The median continuity of care score was higher among patients with diabetes-concordant conditions compared with those with diabetes-discordant conditions, and it declined with additional comorbid conditions in both groups. Greater continuity of care was associated with lower hospital utilisation for older diabetes patients with both concordant and discordant conditions.

Conclusions There is a need for focusing on improving continuity of care and prioritising treatment in older adults with diabetes with any multiple conditions but especially in those with diabetes-discordant conditions (eg, depression).

\section{INTRODUCTION}

Evidence shows that the majority of care for adults with multiple chronic conditions is provided in ambulatory care settings and primary care and is an important locus from
Strengths and limitations of this study

- This population-based study included a large sample size to examine the quality of overall care for older adults with four disease combinations representing the most prevalent clusters of concurrent conditions across multimorbidity groupings.

- The study takes advantage of linked patient-level health administrative databases with detailed demographic and clinical information.

- The study used process of care measures for assessing ambulatory care among older adults with selected disease combinations that were developed using a Delphi technique integrating clinical expertise with systematic reviews of each disease combination.

- The study measures were limited to those available in Ontario administrative data.

- Data regarding other covariates (eg, severity of selected conditions and frailty) and health outcomes (eg, quality of life) were not available for this cohort and should be explored in future research.

which to develop approaches of care to better meet the needs of this population. ${ }^{12}$ Older adults are more likely than younger individuals to have comorbid chronic conditions that can be complex and difficult to manage. ${ }^{3} 4$ Recent research has demonstrated that more than $90 \%$ of older adults with diabetes in Ontario had at least one comorbid condition. ${ }^{5}$ In particular, arthritis, other cardiovascular conditions and mood disorders also commonly appear in older adults with diabetes. ${ }^{35}$ Hypertension consistently appears as a comorbidity in older adults with diabetes. ${ }^{356}$

A growing body of evidence shows that people with multiple chronic conditions are more likely to experience negative health outcomes, including increased healthcare utilisation, poor quality of life and increased care costs compared with those a with single 
disease. ${ }^{7-10}$ Prior research found that Ontarians with three or more diagnoses had $56 \%$ more primary care visits, $76 \%$ more specialist visits, $256 \%$ more inpatient hospital stays, $11 \%$ more emergency department visits and $68 \%$ more prescriptions, as compared with those with a single condition. ${ }^{11} 12$ Primary care physicians face difficulties in addressing the complex multifaceted needs of older adults with multiple chronic conditions. ${ }^{13}$ Treatment of people with multiple chronic conditions often requires 'trade-off' decisions, because current clinical guidelines may be impractical in the presence of multiple chronic conditions. $^{14}$

Treating one condition in older diabetes patients with comorbid conditions may cause undesirable consequences with regard to their other conditions. The optimal approach to treat patients with any combination of coexisting diseases is not the same as the sum of treatments for the separate diseases. ${ }^{15}$ Meanwhile, a single condition focus in both clinical care and research persists and limits the assessment of care for the whole person with multiple chronic conditions. There is a need to understand how diabetes treatment and that for co-occurring comorbid chronic conditions varies depending on the specific comorbid conditions and to assess the relationships between specific quality of care measures across combinations of conditions and adverse events such as hospital admission.

To address this knowledge gap, the objectives of this study were to: (1) explore whether the quality of care for older people with diabetes is differentially affected by types and number of comorbid chronic conditions; and (2) examine the association between quality of care (process) measures and the likelihood of all-cause hospitalisations among older adults with diabetes with selected comorbid conditions.

\section{METHODS}

\section{Study design and study participants}

This was a retrospective cohort study conducted in Ontario, Canada, using linked provincial health administrative databases. We identified a cohort of people 65 years of age and older who had diabetes as of 1 April 2010, using the Ontario Diabetes Database (ODD). The ODD is a validated database that identifies all adults aged 20 years and older with diabetes in Ontario from 1 April 1991. ${ }^{1617}$ The ODD has demonstrated high sensitivity $(86 \%)$ and specificity $(97 \%)$ in identifying individuals compared with primary care electronic medical records. ${ }^{1618}$ We also ascertained concurrent diagnoses of hypertension, chronic ischaemic heart disease, osteoarthritis and depression. All diagnoses (including diabetes, hypertension, ischaemic heart diseases, osteoarthritis and depression) were identified if they had either one hospital admission or two ambulatory physician claims with each respective diagnosis within 2 years. Depression in this study connotes major depression and dysthymia, since most clinical practice guidelines only address treatment of major depression. ${ }^{19}$ Each condition was defined with health administrative data from 1 April 2001 to 1 April 2010 (index date). Patients were excluded if they fell under the following criteria: had an invalid health card number, were younger than 65 years or older than 105 years old, died before the index date (1 April 2010) or had no contact with the healthcare system in the last 5 years before the index date.

The selected five chronic diseases were categorised into two groups by comorbidity type relative to diabetes, ${ }^{20}$ including: (1) diabetes-concordant conditions that share a common management plan: (A) diabetes with comorbid hypertension and without chronic ischaemic heart disease and (B) diabetes with comorbid hypertension and chronic ischaemic heart disease, and (2) diabetesdiscordant conditions that are not directly related in the disease management plan: (A) diabetes with comorbid osteoarthritis and without major depression and (B) diabetes with osteoarthritis and major depression). These four disease combinations represented most prevalent clusters of concurrent conditions across multimorbidity groupings based on the prior research results. ${ }^{3}$

\section{Data sources}

Data sources for this study included: the Canadian Institute for Health Information Discharge Abstract Database (DAD), which consists of data on all hospital discharges in Ontario; the Ontario Health Insurance Plan (OHIP) claims database that contains information on patient contact with physicians in both ambulatory and hospital settings; the Registered Persons Database, which contains information regarding the demographics of persons eligible for healthcare coverage in Ontario; the Client Agency Program Enrolment database, which identifies patients belonging to the primary care models; and the Ontario Drug Benefit claims database that contains comprehensive records of prescription medications dispensed in outpatient pharmacies to Ontario residents eligible for public drug coverage, specifically those aged 65 years and over. Canada census data were also used to derive population estimates by age and sex in each year. All databases were linked using unique, encoded identifiers and analysed at the Institute of Clinical Evaluative Sciences in Toronto, Ontario.

All provinces in Canada hold administrative data for the full population under a universal healthcare system that is similar to other health systems internationally including diagnoses and utilisation from physician, hospital and pharmacy billing data.

\section{Study outcome}

The study outcome was the likelihood of having at least one hospital admission in each year, during the study period, 1 April 2010-3 March 2014. This outcome measure had a value 1 (yes) if any study subject had at least one all-cause hospitalisation in each year and 0 (no) if not. 
Table 1 Process of care measures

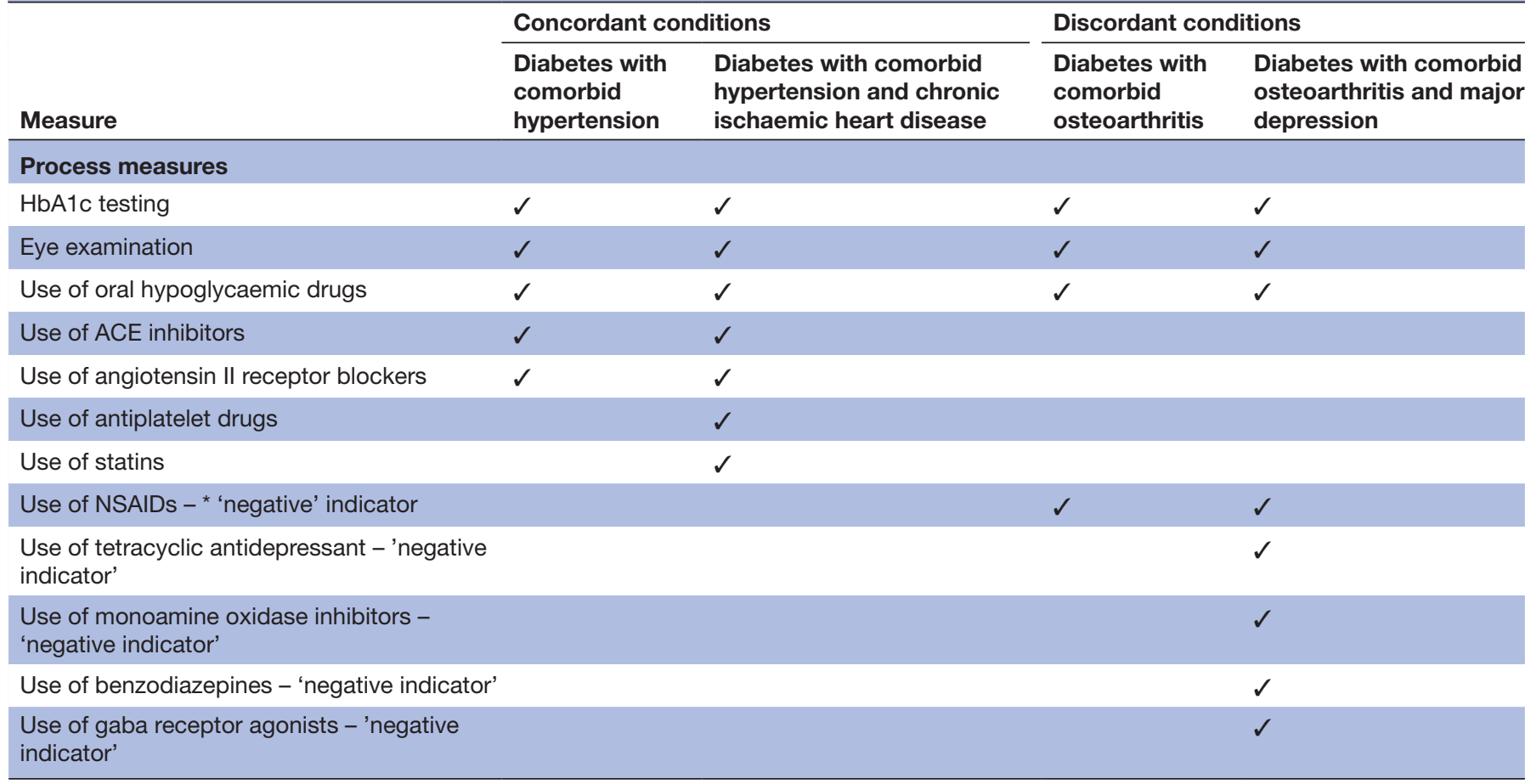

*'Negative' indicators related to contraindicated processes because they increase the risk of adverse outcomes.

HbA1c, glycated haemoglobin; NSAIDs, non-steroidal anti-inflammatory drugs.

\section{Process of care measures}

This study uses process and outcome measures for diabetes with comorbidities. A specific set of process and outcome measures was developed by means of a Delphi panel $^{21}$ for assessing the quality of care for older adults with each particular disease combination in ambulatory care settings (table 1). Delphi participants purposefully selected a list of indicators in the context of assessing care of older adults with diabetes and specific comorbid chronic conditions.

Processes of care measures were calculated using the same data sources. The measures included: having one or two glycated haemoglobin (HbA1c) tests per year, having three or more HbAlc tests per year, annual eye examination, use of oral hypoglycaemic drugs in each, use of ACE inhibitors in each, use of angiotensin II receptor blockers (ARBs) in each, number of prescribed drugs in each year $^{22} 23$ and use of non-steroidal anti-inflammatory drugs (NSAIDs) in each year. There were also a series of 'negative' indicators that related to contraindicated processes because they increase the risk of adverse outcomes. Theses included use of tetracyclic antidepressants in each year, use of monoamine oxidase inhibitors in each year, use of gaba receptor agonists in each year and use of benzodiazepines in each year. Continuity of care was measured use the Bice Continuity of Care (COC) index that measures both the dispersion and concentration of care among all providers seen and can be adapted to capture aspects of the coordination of care by attributing referral visits back to the referring provider. ${ }^{2425}$ To align with the prior research in this population, we categorised COC index as having a high versus low continuity or concentration of care using the median COC score for each selected disease combination, respectively. ${ }^{26-28}$

\section{Covariates}

We included patient demographic and clinical factors that could confound the relationship between process of care measures and the study outcomes as covariates in all regression models, including: (1) age (coded as 65-74, 75-84, 85-94, 95 years and over), (2) sex (coded as male/ female), (3) geographic location measured by the Rurality Index of Ontario (RIO) $(\leq 40=$ non-rural and $>40=$ rural $),{ }^{29}$ (4) neighbourhood income quintile (ranging from Q1=lowest income to Q5=highest income), ${ }^{30}$ (5) level of multimorbidity (ie, chronic disease burden) as the number of prevalent chronic conditions in addition to the five selected chronic conditions, ${ }^{35}$ including heart failure, acute myocardial infarction, cardiac arrhythmia, stroke, COPD, asthma, cancer, renal disease, other mood disorders, dementia, psychiatric diseases other than mood disorders and dementia, rheumatoid arthritis or osteoporosis (online supplementary appendix 1); this was coded as zero, one, two, three, four or five-plus, as well as (6) the duration of each condition of interest in the particular disease combinations, including diabetes, hypertension, chronic ischaemic heart disease, major depression or osteoarthritis (in years). We also included health system factors including (7) patient's primary care model categorised into: (A) non-capitated models where physicians largely operate on a fee-for-service basis, (B) capitated rostered models and (C) capitated+, including family 
health teams and other rostered models with additional incentives for interdisciplinary care ${ }^{3132}$ and (8) number of primary care visits, including office-based visits with a general practitioner or family physician.

\section{Statistical analysis}

All analyses were stratified by condition combinations (diabetes with each of hypertension, hypertension with ischaemic heart disease, osteoarthritis and osteoarthritis and depression) for which quality indicators were established.

Participant characteristics were described using proportions, means (SD) and medians (IQR) where appropriate. Marginal logistic models using a generalised estimating equations approach (PROC GENMOD in SAS) were performed to examine associations between the likelihood of hospitalisations during the follow-up period, from 2011 to 2014, based on the process of care measures in the year prior, among older adults with each particular disease combination, respectively. Generalised estimating equations were used to make inferences about the mean response in the population, to make inference about differences in quality of care between two groups of patients, to account for within-subject correlation among the repeated responses, to deal with different numbers of observations per patient and to estimate model parameters, using the available information. ${ }^{33}$ Risk estimates are presented as adjusted ORs (AORs) and corresponding 95\% CIs. All data analyses were performed with SAS package V.9.3. The level of statistical significance was considered $\mathrm{p}$ less than 0.05 .

\section{Patient and public involvement}

Patients or the public were not involved in the design, or conduct, or reporting, or dissemination of our research.

\section{RESULTS}

Table 2 presents baseline characteristics of the study population. The cohort of older adults with diabetes with comorbid hypertension and without chronic ischaemic heart disease included 273592 patients, while the cohort with comorbid hypertension and chronic ischaemic heart disease contained 141947 patients. The cohort of older adults with diabetes with comorbid osteoarthritis and without depression included 255214 patients, while the cohort of older adults with diabetes with comorbid osteoarthritis and major depression contained 2444 individuals.

About $85 \%$ of diabetes patients were between 65 and 84 years, and over half were female. Women were more prevalent than men in the cohort of diabetes patients with comorbid osteoarthritis and depression. Nearly half of the people comorbid with hypertension (44.7\%) and $76.6 \%$ of patients with comorbid osteoarthritis and depression were prescribed 11 or more medications. More than $25 \%$ of the latter group were classified as having five or more concurrent conditions among those measured in this study. The majority of older diabetes patients with comorbid conditions were living in lower income neighbourhoods.

Table 3 presents the distribution of process measures and all-cause hospitalisations among older adults with four selected disease combinations. The proportion of patients who had 1 or $2 \mathrm{HbA1c}$ tests per year or were prescribed oral hypoglycaemic drugs was lower in diabetes patients with two comorbid conditions compared with those with one comorbid condition (both concordant and discordant); this decline was more significant in patients with comorbid osteoarthritis and major depression. The proportion of patients who had an annual eye examination performed was slightly higher in diabetes patients with two concordant comorbid conditions than that in diabetes patients with comorbid hypertension only. The median score of continuity of care was greater in older diabetes patients with concordant rather than discordant comorbid conditions $(0.57$ vs 0.53 in patients with one concordant vs discordant condition); however, it declined with additional comorbid conditions, especially in those with discordant conditions (0.36 in patients with comorbid osteoarthritis and major depression).

The proportion of patients who were prescribed ACE inhibitors and ARBs was higher in older adults with comorbid hypertension and chronic ischaemic heart disease compared with those without ischaemic heart disease. About $14 \%$ of older diabetes patients with comorbid osteoarthritis with and without major depression were prescribed tetracyclic antidepressants; $20 \%$ were prescribed NSAID therapy; and 40\% were prescribed benzodiazepines. The incidence of all-cause hospitalisations markedly increased in older adults with diabetes with 2 versus 1 selected comorbid condition, especially in those with discordant conditions.

Table 4 presents results of multivariable association of process of care indicators and all-cause hospitalisations among older adults with four selected disease combinations. Meeting HbAlc testing frequency goals, having an annual eye exam or oral hypoglycemic drug therapy were significantly associated with reduction in the likelihood of all-cause hospitalisations in older people with diabetes comorbid with concordant (with comorbid hypertension with or without chronic ischaemic heart disease) and diabetes patients with comorbid osteoarthritis only. In diabetes patients comorbid with osteoarthritis and depression, having an annual eye exam was significantly associated with reduction in the likelihood of all-cause hospitalisations. There was no association between use of ACE inhibitors or ARB therapy and the likelihood of hospitalisations in patients with diabetes with comorbid hypertension and chronic ischaemic heart disease.

Antiplatelet therapy was significantly associated with an increase in the likelihood of all-cause hospitalisations among older adults with comorbid hypertension and chronic ischaemic heart disease. There was a very marginal though significant association between NSAID therapy and reduction in all-cause hospitalisations in 
Table 2 Baseline characteristics

\begin{tabular}{|c|c|c|c|c|}
\hline Characteristic & $\begin{array}{l}\text { Diabetes with } \\
\text { comorbid } \\
\text { hypertension }\end{array}$ & $\begin{array}{l}\text { Diabetes with comorbid } \\
\text { hypertension and chronic } \\
\text { ischaemic heart disease }\end{array}$ & $\begin{array}{l}\text { Diabetes with } \\
\text { comorbid } \\
\text { osteoarthritis }\end{array}$ & $\begin{array}{l}\text { Diabetes with comorbid } \\
\text { osteoarthritis and major } \\
\text { depression }\end{array}$ \\
\hline Number of individuals & 273592 & 141947 & 255214 & 2444 \\
\hline Age in years, mean (SD) & $76.2(7.18)$ & $77.4(7.12)$ & $76.6(7.24)$ & $75.7(7.12)$ \\
\hline \multicolumn{5}{|l|}{ Age in groups, $n(\%)$ (years) } \\
\hline $65-74$ & $127469(46.6)$ & $54593(38.4)$ & 112046 (43.9) & $1194(48.9)$ \\
\hline $75-84$ & $106336(38.9)$ & $61.883(43.6)$ & $102717(40.2)$ & $906(37.1)$ \\
\hline $85-94$ & $37194(13.6)$ & $23950(16.9)$ & $37900(14.9)$ & $333(13.6)$ \\
\hline $95+$ & $2593(0.9)$ & $1521(1.1)$ & $2551(1.0)$ & $11(0.4)$ \\
\hline \multicolumn{5}{|l|}{ Sex, n (\%) } \\
\hline Female & $154565(56.5)$ & $81987(57.8)$ & $139951(54.8)$ & $1545(63.2)$ \\
\hline Male & $119027(43.5)$ & $59960(42.2)$ & $115263(45.2)$ & 899 (36.8) \\
\hline Number of drugs, mean (SD) & $10.6(5.89)$ & $13.4(6.52)$ & $12.1(6.42)$ & $17.1(7.6)$ \\
\hline \multicolumn{5}{|l|}{ Number of drugs, $\mathrm{n}(\%)$} \\
\hline$\leq 5$ drugs & $48210(17.6)$ & $10924(7.7)$ & 33768 (13.2) & $136(5.7)$ \\
\hline $6-10$ drugs & $103032(37.7)$ & $39583(27.9)$ & $80695(31.6)$ & $433(17.7)$ \\
\hline$\geq 11$ drugs & $122350(44.7)$ & $91440(64.4)$ & $140751(55.2)$ & $1875(76.6)$ \\
\hline \multicolumn{5}{|l|}{ Income quintiles, n (\%) } \\
\hline Q1 lowest income & $57053(21.7)$ & $29478(22.0)$ & $53174(21.6)$ & $589(26.1)$ \\
\hline Q2 & $58237(22.1)$ & $29496(22.0)$ & $53884(22.0)$ & $504(22.3)$ \\
\hline Q3 & $52967(20.1)$ & $26765(20.0)$ & $48922(20.0)$ & $414(18.4)$ \\
\hline Q4 & $50668(19.2)$ & $25649(19.1)$ & $47143(19.3)$ & $360(15.0)$ \\
\hline Q5 highest income & $44653(16.9)$ & $22657(16.9)$ & $41855(17.1)$ & $388(17.2)$ \\
\hline \multicolumn{5}{|l|}{ *RIO index, n (\%) } \\
\hline$\leq 40$ (urban) & $214443(78.4)$ & 131065 (92.3) & $237312(93.0)$ & $2293(93.8)$ \\
\hline$>40$ (rural) & $59149(21.6)$ & $10882(7.7)$ & $17, .902(7.0)$ & $151(6.2)$ \\
\hline \multicolumn{5}{|l|}{ †Primary care models, $\mathrm{n}(\%)$} \\
\hline Fee-for-service & 140465 (68.3) & 120557 (63.7) & $128522(69.2)$ & $1450(67.8)$ \\
\hline Capitated+ & 29203 (14.2) & $26685(14.1)$ & $26930(14.5)$ & 297 (13.9) \\
\hline Capitated & $35990(17.5)$ & $42015(22.2)$ & $30273(16.3)$ & 391 (18.3) \\
\hline \multicolumn{5}{|l|}{ Comorbidities, n (\%) } \\
\hline $0 \mathrm{CC}$ & $59149(21.6)$ & $15859(11.2)$ & $12061(4.7)$ & $77(3.1)$ \\
\hline $1 \mathrm{CC}$ & $88411(32.3)$ & $33105(23.3)$ & $58547(22.9)$ & $335(13.7)$ \\
\hline $2 \mathrm{CC}$ & $64965(23.7)$ & $34350(24.2)$ & $67635(26.5)$ & $495(20.3)$ \\
\hline $3 \mathrm{CC}$ & $34914(12.8)$ & $26547(18.7)$ & $50641(19.8)$ & $490(20.1)$ \\
\hline $4 \mathrm{CC}$ & $16382(6.0)$ & $16972(12.0)$ & $32778(12.8)$ & $428(17.5)$ \\
\hline 5 or more CC & $9771(3.6)$ & $15114(10.7)$ & $33552(13.3)$ & $619(25.3)$ \\
\hline $\begin{array}{l}\text { Number of primary care visits, } \\
\text { mean (SD) }\end{array}$ & $6.1(5.77)$ & $7.6(6.99)$ & $7.34(6.60)$ & $7.8(7.4)$ \\
\hline $\begin{array}{l}\text { Duration of diabetes in years, } \\
\text { mean (SD) }\end{array}$ & $9.90(5.80)$ & $10.7(6.02)$ & $10.0(5.88)$ & $10.3(6.01)$ \\
\hline $\begin{array}{l}\text { Duration of hypertension in } \\
\text { years, mean (SD) }\end{array}$ & $13.1(5.65)$ & $13.8(5.44)$ & - & - \\
\hline $\begin{array}{l}\text { Duration of chronic ischaemic } \\
\text { heart disease, mean (SD) }\end{array}$ & - & $7.13(2.68)$ & - & - \\
\hline $\begin{array}{l}\text { Duration of osteoarthritis in } \\
\text { years, mean (SD) }\end{array}$ & - & - & $7.17(2.57)$ & 7.4 (2.61) \\
\hline
\end{tabular}


Table 2 Continued

\begin{tabular}{lcccc} 
Characteristic & $\begin{array}{l}\text { Diabetes with } \\
\text { comorbid } \\
\text { hypertension }\end{array}$ & $\begin{array}{l}\text { Diabetes with comorbid } \\
\text { hypertension and chronic } \\
\text { ischaemic heart disease }\end{array}$ & $\begin{array}{l}\text { Diabetes with } \\
\text { comorbid } \\
\text { osteoarthritis }\end{array}$ & $\begin{array}{l}\text { Diabetes with comorbid } \\
\text { osteoarthritis and major } \\
\text { depression }\end{array}$ \\
\hline $\begin{array}{l}\text { Duration of major depression, } \\
\text { mean (SD) }\end{array}$ & - & - & - & $3.3(1.62)$ \\
\hline
\end{tabular}

${ }^{*}$ Geographic location ( $\leq 40=$ non-rural; $>40=$ rural).

†Non-capitated models include non-rostered models and those that operate on a fee-for-service basis; capitated models include family health networks and family health organisations operating on a capitation funding scheme; and the capitated+models include family health teams and other rostered models operating on a capitated funding scheme with additional incentives for interdisciplinary care.

CC, comorbid condition; RIO, Rurality Index of Ontario.

older diabetes patients with comorbid osteoarthritis that was not significant when depression was also present. There was a significant association between use of benzodiazepines and increase in all-cause hospitalisations, while there was no association found between use of tetracyclic antidepressants and all-cause hospitalisations among patients with comorbid osteoarthritis and depression. The study findings suggest an association between greater continuity of care and reduction in all-cause hospitalisations in older people with diabetes with comorbid concordant and discordant conditions. The likelihood of all-cause hospitalisations increased by $6 \%$ with each additional filled prescription among older adults with comorbid concordant or discordant conditions.

\section{DISCUSSION}

The study findings demonstrate that the quality of overall care declined in older adults with diabetes with each additional selected comorbid condition and was especially low for those with comorbid osteoarthritis and major depression. Therefore, older patients with diabetes with comorbid osteoarthritis with or without major depression need more targeted interventions and collaboration between healthcare providers to improve quality of care and reduce hospitalisation. These findings can help inform clinicians and policy makers in developing strategies for subpopulations at risk. Previous research demonstrates that people with diabetes with two or more

Table 3 Distribution of process and outcome measures among adults with diabetes with comorbidities

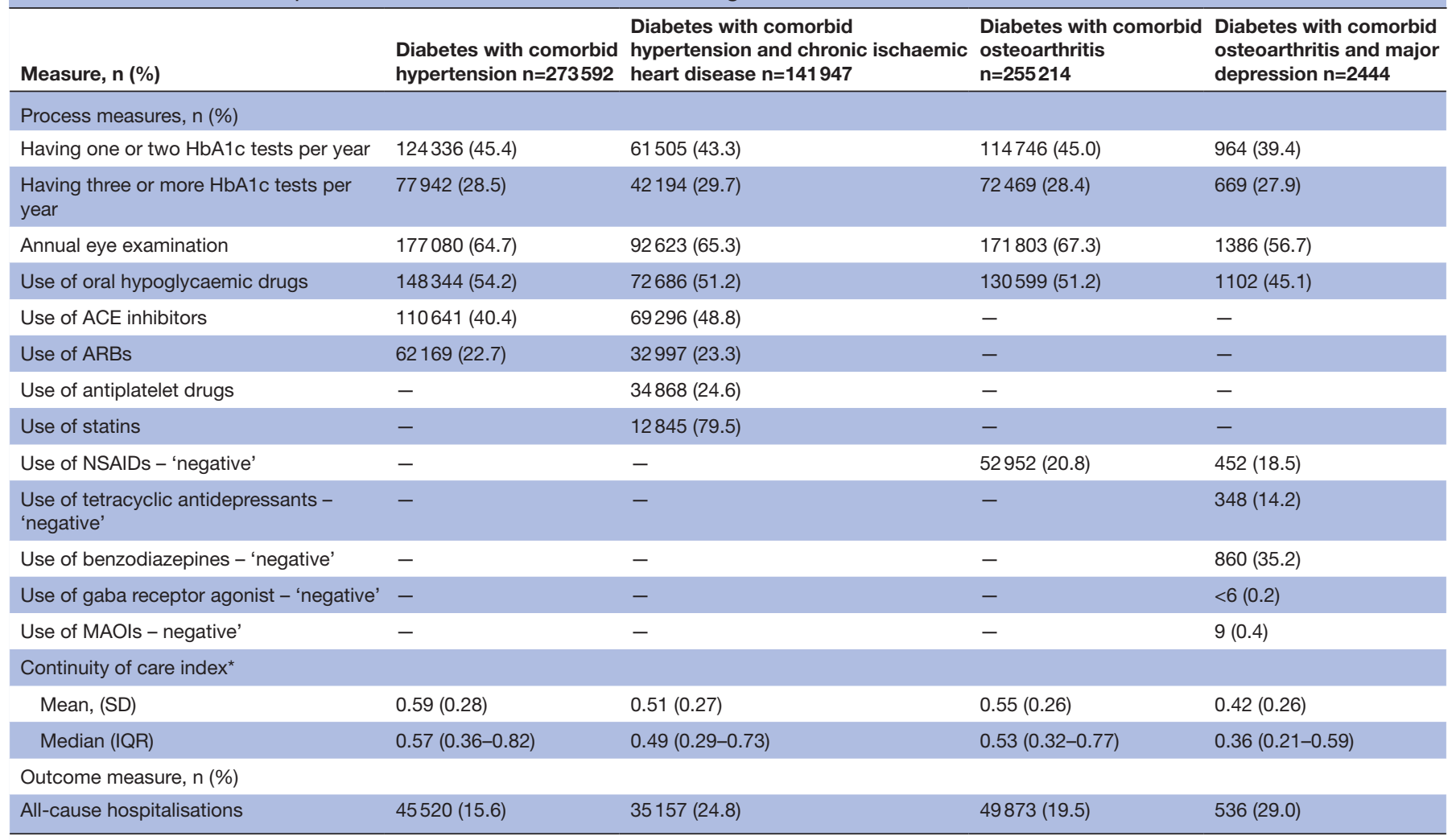

${ }^{*}$ Calculated using the Bice index.

ARBs, angiotensin II receptor blockers; HbA1c, glycated haemoglobin; MAOIs, monoamine oxidase inhibitors; NSAID, non-steroidal anti-inflammatory drugs. 
Table 4 Multivariable associations between process measures and the likelihood of all-cause hospitalisations among older adults with selected disease combinations

\begin{tabular}{|c|c|c|c|c|}
\hline & $\begin{array}{l}\text { Diabetes with } \\
\text { comorbid } \\
\text { hypertension } \\
\mathrm{n}=273592 \\
\end{array}$ & $\begin{array}{l}\text { Diabetes with } \\
\text { comorbid } \\
\text { hypertension and } \\
\text { chronic ischaemic } \\
\text { heart disease } \\
\mathrm{n}=141947\end{array}$ & $\begin{array}{l}\text { Diabetes with } \\
\text { comorbid } \\
\text { osteoarthritis } \\
\mathrm{n}=\mathbf{2 5 5 2 1 4} \\
\end{array}$ & $\begin{array}{l}\text { Diabetes with } \\
\text { comorbid } \\
\text { osteoarthritis and } \\
\text { major depression } \\
\mathrm{n}=2444\end{array}$ \\
\hline Characteristic & $\begin{array}{l}\text { All-cause } \\
\text { hospitalisations } \\
\text { AOR }(95 \% \mathrm{Cl})\end{array}$ & $\begin{array}{l}\text { All-cause } \\
\text { hospitalisations } \\
\text { AOR }(95 \% \mathrm{Cl})\end{array}$ & $\begin{array}{l}\text { All-cause } \\
\text { hospitalisations } \\
\text { AOR }(95 \% \mathrm{Cl})\end{array}$ & $\begin{array}{l}\text { All-cause } \\
\text { hospitalisations } \\
\text { AOR }(95 \% \mathrm{Cl})\end{array}$ \\
\hline \multicolumn{5}{|l|}{ Having $\mathrm{HbA1c}$ tests } \\
\hline No & Ref. & Ref. & Ref. & Ref. \\
\hline 1 or $2 \mathrm{HbA} 1 \mathrm{c}$ tests & 0.90 (0.88 to 0.92$)$ & 0.88 (0.85 to 0.91$)$ & 0.88 (0.86 to 0.90$)$ & $0.93(0.76$ to 1.13$)$ \\
\hline 3 or more $\mathrm{HbA} 1 \mathrm{c}$ tests & 0.84 (0.82 to 0.86$)$ & 0.86 (0.83 to 0.88$)$ & 0.83 (0.81 to 0.85$)$ & $0.82(0.69$ to 1.03$)$ \\
\hline \multicolumn{5}{|l|}{ Annual eye examination } \\
\hline No & Ref. & Ref. & Ref. & Ref. \\
\hline Yes & 0.85 (0.84 to 0.87$)$ & 0.90 (0.88 to 0.92$)$ & 0.89 (0.87 to 0.91$)$ & 0.85 (0.75 to 0.97$)$ \\
\hline \multicolumn{5}{|c|}{ Use of oral hypoglycaemic drugs } \\
\hline No & Ref. & Ref. & Ref. & Ref. \\
\hline Yes & 0.88 (0.86 to 0.90$)$ & 0.88 (0.86 to 0.90$)$ & $0.92(0.89$ to 0.93$)$ & $0.93(0.78$ to 1.10$)$ \\
\hline \multicolumn{5}{|l|}{ Use of ACE inhibitors } \\
\hline No & Ref. & Ref. & - & - \\
\hline Yes & 1.04 (0.99 to 1.06$)$ & 1.03 (0.98 to 1.05$)$ & - & - \\
\hline \multicolumn{5}{|l|}{ Use of ARBs } \\
\hline No & Ref. & Ref. & - & - \\
\hline Yes & 0.93 (0.92 to 1.02$)$ & 0.98 (0.96 to 1.01$)$ & - & - \\
\hline \multicolumn{5}{|l|}{ Use of antiplatelet drugs } \\
\hline No & - & Ref. & - & - \\
\hline Yes & - & 1.08 (1.06 to 1.11$)$ & - & - \\
\hline \multicolumn{5}{|l|}{ Use of statins } \\
\hline No & - & Ref. & - & - \\
\hline Yes & - & 0.89 (0.86 to 0.92$)$ & - & - \\
\hline \multicolumn{5}{|l|}{ Use of NSAIDs } \\
\hline No & - & - & Ref. & Ref. \\
\hline Yes & - & - & 0.99 (0.97 to 0.99) & 0.99 (0.88 to 1.12$)$ \\
\hline \multicolumn{5}{|c|}{ Use of tetracyclic antidepressants } \\
\hline No & - & - & - & Ref. \\
\hline Yes & - & - & - & 1.14 (0.86 to 1.32$)$ \\
\hline \multicolumn{5}{|l|}{ Use of benzodiazepines } \\
\hline No & - & - & - & Ref. \\
\hline Yes & - & - & - & 1.33 (1.20 to 1.48$)$ \\
\hline \multicolumn{5}{|c|}{ Continuity of Care (COC) index* } \\
\hline $\mathrm{COC} \leq$ median value & Ref. & Ref. & Ref. & Ref. \\
\hline COC >median value & 0.70 (0.69 to 0.72$)$ & $0.74(0.72$ to 0.77$)$ & $0.73(0.72$ to 0.74$)$ & 0.84 (0.72 to 0.93$)$ \\
\hline Number of drugs & $1.06(1.04$ to 1.07$)$ & 1.05 (1.02 to 1.07$)$ & 1.06 (1.04 to 1.08$)$ & 1.06 (1.05 to 1.07$)$ \\
\hline Age & 1.04 (1.03 to 1.05$)$ & 1.03 (1.02 to 1.04$)$ & 1.03 (1.02 to 1.04$)$ & 1.02 (1.01 to 1.04$)$ \\
\hline \multicolumn{5}{|l|}{ Sex } \\
\hline Female & Ref. & Ref. & Ref. & Ref. \\
\hline
\end{tabular}


Table 4 Continued

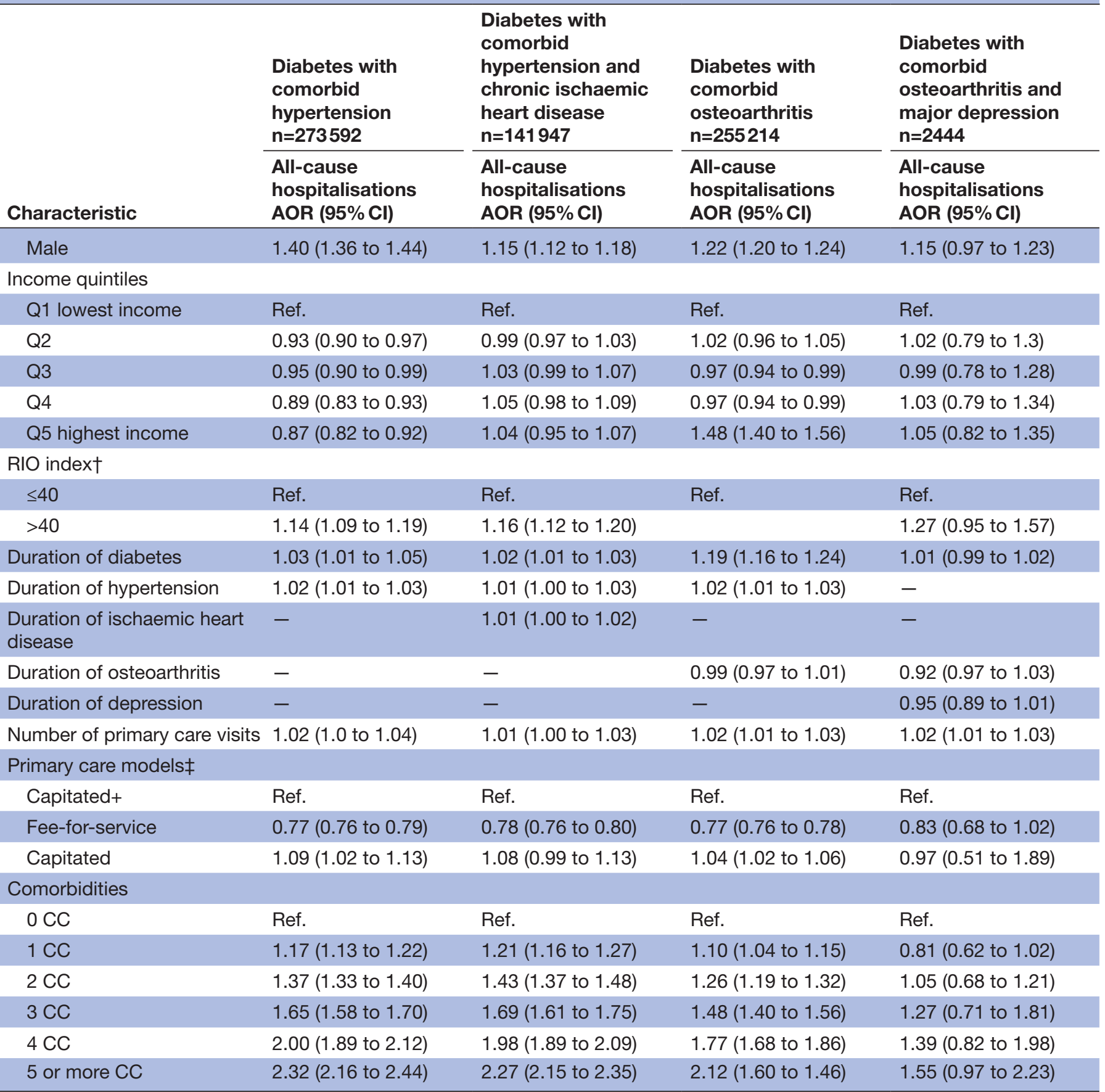

${ }^{*}$ Calculated using the Bice index.

†Geographic location ( $\leq 40=$ non-rural; $>40=$ rural).

$\ddagger$ Noncapitated models include nonrostered models and those that operate on a fee-for-service basis; capitated models include family health networks and family health organisations operating on a capitation funding scheme; and the capitated + models include family health teams and other rostered models operating on a capitated funding scheme with additional incentives for interdisciplinary care.

AOR, adjusted OR; ARBs, angiotensin II receptor blockers; HbA1c, glycated haemoglobin; NSAIDs, non-steroidal anti-inflammatory drugs.

comorbid conditions were more likely to achieve the target HbAlc testing frequency or have annual eye examination compared with those with no or one comorbid condition. ${ }^{34}$ However, the authors used diabetes care measures to assess the role of number of concordant and discordant conditions on the achievement of diabetes testing goals without specifying individual concordant and discordant conditions, despite the fact that certain conditions may have a greater impact on diabetes care than other conditions. Another study demonstrates that as compared with diabetes patients without comorbidities, those with concordant comorbid conditions had an increased likelihood of receiving reviews of medications 
and blood pressure examinations, while discordant comorbidities do not compete with diabetes care. ${ }^{35}$

The study findings support the underlying premise of the framework of Concordance and Discordance proposed by Piette and Kerr that hypothesises that the effects of comorbidity on patients with diabetes differ depending on the nature of comorbid conditions. ${ }^{20}$ The literature suggests that physicians may prioritise treatment of concordant conditions over discordant conditions, because a single treatment plan can improve the status of more than one condition. ${ }^{36}$ Blood pressure and cholesterol targets, increased physical activity, as well as the use of antihypertensive therapy are identical for patients with diabetes and cardiovascular conditions, including hypertension and ischaemic heart disease. ${ }^{37}$ Thus, for the majority of patients, management of cardiovascular conditions enhances the management of diabetes.

The study findings suggest an association between greater continuity of care and reduction in all-cause hospitalisations in older people with diabetes with comorbid concordant and discordant conditions. This finding is consistent with other study results. ${ }^{38-40}$ Gruneir and colleagues ${ }^{26}$ found that the risk of hospitalisations was reduced in people with one or more chronic conditions, when visits and referrals are concentrated with a single physician.

We found that older diabetes patients with comorbidities, especially with discordant conditions, are likely to be prescribed a large number of drugs, and the more drugs they are prescribed, the higher is the risk of hospitalisations. This study finding is consistent with previous research results. ${ }^{4142}$ The study results demonstrate that the mean number of prescribed drugs increased in older diabetes patients with 2 versus 1 comorbid condition, especially in those with discordant conditions (17 vs 12 prescriptions). There was no association observed between use of ACE inhibitors and ARB therapy and the likelihood of hospitalisations in patients with diabetes with comorbid hypertension and chronic ischaemic heart disease. The information regarding the benefit of ACE inhibitors or ARBs on vascular protection among older adults with diabetes remains controversial in diabetes patients with comorbidities. The study findings found a negligible association between NSAID therapy and reduction in all-cause hospitalisations in patients with comorbid osteoarthritis that was not significant when depression was also present. While the recent review of evidence from the Osteoarthritis Research Society International suggests that use of NSAID therapy for osteoarthritis management provides better efficacy than acetaminophen for relief of chronic inflammatory pain, ${ }^{43}$ this was not substantially related to all-cause hospitalisations.

The incidence of hospitalisations markedly increased in older adults with diabetes with 2 versus 1 selected comorbid condition, especially in those with discordant conditions (diabetes comorbid with osteoarthritis and depression). This study finding is consistent with previous research that found a higher rate of hospital admission among people with diabetes with discordant than concordant comorbid conditions, especially in those with mental conditions. ${ }^{44}$ A recent study indicated that there is a trend of increasing use of healthcare services, including hospitalisations, emergency department visits and physician visits, with increase in number of comorbid conditions among older adults with diabetes. ${ }^{24}$

\section{Strengths and limitations}

Our study sheds light on limited research evidence regarding the assessment of the overall quality of care among older adults with diabetes comorbid with specific concordant/discordant comorbid conditions. The study cohort was drawn from the entire Ontario population with a diagnosis of diabetes aged 65 years and older. Administrative data have the advantage of being population-based and are relatively inexpensive compared with the other potential sources of data for ambulatory care evaluation. We used validated algorithms to define chronic diagnoses. In our study, multiple databases were used to ascertain the cases, including hospital stay (DAD

), physician visits (OHIP) and validated disease cohorts. The specific sets of process of care measures, as judged to be relevant by the Delphi panel, ${ }^{21}$ were used for assessing clinical aspects of ambulatory care among older adults with four selected disease combinations. The development of process of care measures integrated clinical expertise with scientific evidence form systematic research.

Nonetheless, the results of the study should be interpreted in light of the following limitations. The study measures identified by the Delphi panel were purposively limited to those available in Ontario administrative data. This restricted measurement of important clinical factors such as disease severity, patient disability and frailty, the availability of social supports or caregivers and mobility or aids used to mitigate functional impairment. We lacked data related to laboratory tests done in hospitals or paid for privately. Ambulatory prescriptions and tests represent the majority of the care that patients receive over the course of their treatment out of hospital. Several quality measures not measurable in this study, such as blood glucose level control, lifestyle changes, patient education, as well as patient preferences and goals of care and self-management ability, could reveal and explain important aspects of the associations between process of care measures and hospitalisations as reported here. There is a potential for misclassifying people based on their comorbidity profiles.

We were not able to account for severity of selected chronic conditions due to limitation of the administrative data that may lead to biassed estimates. We focused on all-cause hospitalisations, without stratifying by reasons for hospitalisation that could potentially inform interventions. The common chronic coexisting conditions that were selected for this study do not represent all existing comorbidities in patients with diabetes. 


\section{CONCLUSIONS}

For an older diabetes patient with comorbidities, the challenge is to find a way to encourage healthcare providers to manage all chronic conditions collectively instead of focusing on a single disease treatment. This study highlighted the most prevalent multimoribdity clusters among older adults with diabetes, including both concordant and discordant comorbidities. Explicit consideration of multimorbidity clusters among older adults with diabetes is important because appropriate management of individual diseases in isolation may not be optimal for patients with multimorbidity due to unique diseasedisease or disease-treatment interactions. Furthermore, determining specific multimorbidity subgroups among patients with diabetes at increased risk of adverse health outcomes has important policy implications and provides targets for tailored prevention.

Our study showed that the number of conditions was the strongest predictor of hospitalisation but higher achievement on diabetes quality of care measures and physician continuity of care along with fewer prescribed medications were also protective with all-cause hospitalisations. These findings represent opportunities to improve ambulatory care that should lead to reductions in hospital use. Research should focus on the evaluation of quality of care for diabetes patients with comorbidities while developing more robust measurement of health outcomes beyond hospitalisation.

Contributors All coauthors fulfill the criteria required for authorship. WPW was the lead for the creation of the cohort. YP and WPW substantially contributed to the conception, analysis and interpretation of the data for the work and to the drafting of the work. JB, KK and BL substantially contributed to the analysis and interpretation of the data for the work. YP drafted the manuscript. YP and WPW revised the drafting of the work critically for important intellectual content. All authors contributed to the final approval of the version to be published and are in agreement to be accountable for all aspects of the work and in ensuring that questions related to the accuracy or integrity of any part of the work are appropriately investigated and resolved.

Funding This study was supported by Institute of Clinical Evaluative Sciences(ICES), which is funded by an annual grant from the Ontario Ministry of Health and Long-Term Care. This study also received funding from a research grant from a Canadian Institute for Health Research Community Based Primary Health Care Team Grant (\#495120).

Disclaimer The analyses, conclusions, opinions and statements expressed herein are solely those of the authors and do not reflect those of the funding or data sources; no endorsement is intended or should be inferred.

Competing interests None declared.

Patient consent for publication Not required.

Provenance and peer review Not commissioned; externally peer reviewed.

Data availability statement No data are available. The data from this study are held securely in coded format ICES. While data sharing agreements prohibit ICES from making the data publicly available, access may be granted to those who meet prespecified criteria for confidential access, available at https://www.ices.on.ca/ DAS.

Open access This is an open access article distributed in accordance with the Creative Commons Attribution Non Commercial (CC BY-NC 4.0) license, which permits others to distribute, remix, adapt, build upon this work noncommercially, and license their derivative works on different terms, provided the original work is properly cited, appropriate credit is given, any changes made indicated, and the use is non-commercial. See: http://creativecommons.org/ licenses/by-nc/4.0/.
ORCID iDs

Yelena Petrosyan http://orcid.org/0000-0002-4785-0569

Walter P Wodchis http://orcid.org/0000-0003-4738-8447

\section{REFERENCES}

1 Fortin M, Bravo G, Hudon C, et al. Prevalence of multimorbidity among adults seen in family practice. Ann Fam Med 2005;3:223-8.

2 Laux G, Kuehlein T, Rosemann T, et al. Co- and multimorbidity patterns in primary care based on episodes of care: results from the German content project. BMC Health Serv Res 2008;8:14.

3 Koné Pefoyo AJ, Bronskill SE, Gruneir A, et al. The increasing burden and complexity of multimorbidity. BMC Public Health 2015;15:415.

4 Boyd CM, Fortin M. Future of multimorbidity research: how should understanding of multimorbidity inform health system design? Public Health Rev 2010;32:451-74.

5 Gruneir A, Markle-Reid M, Fisher K, et al. Comorbidity burden and health services use in Community-Living older adults with diabetes mellitus: a retrospective cohort study. Can J Diabetes 2016;40:35-42.

6 Barnett K, Mercer SW, Norbury M, et al. Epidemiology of multimorbidity and implications for health care, research, and medical education: a cross-sectional study. The Lancet 2012;380:37-43.

7 Fortin M, Bravo G, Hudon C, et al. Relationship between multimorbidity and health-related quality of life of patients in primary care. Quality of Life Research 2006;15:83-91.

8 Fortin M, Soubhi H, Hudon C, et al. Multimorbidity's many challenges. BMJ 2007;334:1016-7.

9 Fortin M, Bravo G, Hudon C, et al. Relationship between psychological distress and multimorbidity of patients in family practice. Ann Fam Med 2006;4:417-22.

10 Freund T, Kunz CU, Ose D, et al. Patterns of multimorbidity in primary care patients at high risk of future hospitalization. Popul Health Manag 2012;15:119-24.

11 Iron K, Lu H, Manuel D, et al. Using linked health administrative data to assess the clinical and healthcare system impact of chronic diseases in Ontario. Hcq 2011;14:23-7.

12 Glynn LG, Valderas JM, Healy P, et al. The prevalence of multimorbidity in primary care and its effect on health care utilization and cost. Fam Pract 2011;28:516-23.

13 Boyd CM, Darer J, Boult C, et al. Clinical practice guidelines and quality of care for older patients with multiple comorbid diseases: implications for pay for performance. JAMA 2005;294:716-24.

14 Lee L, Heckman G. Meeting the challenges of managing seniors with multiple complex conditions: the central role of primary care. CGS Journal of CME 2012;2:23-7.

15 Wami WM, Buntinx F, Bartholomeeusen S, et al. Influence of chronic comorbidity and medication on the efficacy of treatment in patients with diabetes in general practice. Br J Gen Pract 2013;63:e267-73.

16 Hux JE, Ivis F, Flintoft V, et al. Diabetes in Ontario: determination of prevalence and incidence using a validated administrative data algorithm. Diabetes Care 2002;25:512-6.

17 Hux JE, Tang M. Patterns of prevalence and incidence of diabetes. In: Hux JE, Booth GL, Slaughter PM, et al, eds. Diabetes in Ontario: an ICES practice atlas. Toronto, ON: Institute for Clinical Evaluative Sciences, 2003: 1.1-1.18.

18 Kiran T, Victor JC, Kopp A, et al. The relationship between primary care models and processes of diabetes care in Ontario. Can J Diabetes 2014;38:172-8.

19 Buchanan D, Tourigny-Rivard MF, Cappeliez P, et al. National Guidelines for Seniors' Mental Health: The Assessment and Treatment of Depression. Can J Geriatric 2006;5:S52-8.

20 Piette JD, Kerr EA. The impact of comorbid chronic conditions on diabetes care. Diabetes Care 2006;29:725-31.

21 Petrosyan Y, Barnsley JM, Kuluski K, et al. Quality indicators for ambulatory care for older adults with diabetes and comorbid conditions: a Delphi study. PLoS One 2018;13:e0208888.

22 Calderón-Larrañaga A, Poblador-Plou B, González-Rubio F, et al. Multimorbidity, polypharmacy, referrals, and adverse drug events: are we doing things well? Br J Gen Pract 2012;62:e821-6.

23 Nobili A, Garattini S, Mannucci PM. Multiple diseases and polypharmacy in the elderly: challenges for the internist of the third millennium. J Comorb 2011;1:28-44.

24 Reid R. Defusing the confusion: concepts and measures of continuity of healthcare. Ottawa: Canadian Health Services Research Foundation, 2002.

25 Bice TW, Boxerman SB. A quantitative measure of continuity of care. Med Care 1977;15:347-9. 
26 Gruneir A, Bronskill SE, Maxwell CJ, et al. The association between multimorbidity and hospitalization is modified by individual demographics and physician continuity of care: a retrospective cohort study. BMC Health Serv Res 2016;16:1-9.

27 Petrosyan Y, Bai YQ, Koné Pefoyo AJ, et al. The relationship between diabetes care quality and diabetes-related hospitalizations and the modifying role of comorbidity. Can J Diabetes 2017;41:17-25.

28 Thavorn K, Maxwell CJ, Gruneir A, et al. Effect of socio-demographic factors on the association between multimorbidity and healthcare costs: a population-based, retrospective cohort study. BMJ Open 2017:7:e017264.

29 Kralj B. Measuring Rurality - RIO2008_BASIC:Methodology and Results. Available: https://www.oma.org/Resources/Documents/ 2008RIO-FullTechnicalPaper.pdf [Accessed 17 Sep 2013].

30 Gruneir A, Forrester J, Camacho X, et al. Gender differences in home care clients and admission to long-term care in Ontario, Canada: a population-based retrospective cohort study. BMC Geriatr 2013;13.

31 Kiran T, Victor JC, Kopp A, et al. The relationship between financial incentives and quality of diabetes care in Ontario, Canada. Diabetes Care 2012;35:1038-46.

32 Wooder SD. Primary care compensation models. Ontario Medical Association, 2011.

33 Fitzmaurice GM, Laird NM, Ware JH. Applied longitudinal analysis. 2nd Edition. Hoboken, N.J: Wiley, 2011.

34 Magnan EM, Palta M, Johnson HM, et al. The impact of a patient's concordant and discordant chronic conditions on diabetes care quality measures. J Diabetes Complications 2015;29:288-94.
35 Aung E, Donald M, Coll J, et al. The impact of concordant and discordant comorbidities on patient-assessed quality of diabetes care. Health Expect 2015;18:1621-32.

36 Laiteerapong $\mathrm{N}$, Huang ES, Chin MH. Prioritization of care in adults with diabetes and comorbidity. Ann N Y Acad Sci 2011;1243:69-87.

37 American Diabetes Association. Standards of medical care in diabetes-2011. Diabetes Care;34:S11-61.

38 Menec VH, Sirski M, Attawar D, et al. Does continuity of care with a family physician reduce hospitalizations among older adults? $J$ Health Serv Res Policy 2006;11:196-201.

39 Saultz JW, Lochner J. Interpersonal continuity of care and care outcomes: a critical review. Ann Fam Med 2005;3:159-66.

40 Worall G, Knight J. Continuity of care is good for elderly people with diabetes. retrospective cohort study of mortality and hospitalization. Canadian Family Physician 2011;57:e16-20.

41 Flaherty JH, Perry HM. 3Rd, Lynchard Gs, Morley JE. polypharmacy and hospitalization among older home care patients. J Gerontol $A$ Biol Sci Med Sci 2000;55:M554-9.

42 Sganga F, Landi F, Ruggiero C, et al. Polypharmacy and health outcomes among older adults discharged from Hospital: results from the crime study. Geriatr Gerontol Int 2015;15:141-6.

43 Zhang W, Nuki G, Moskowitz RW, et al. OARSI recommendations for the management of hip and knee osteoarthritis: Part III: changes in evidence following systematic cumulative update of research published through January 2009. Osteoarthritis Cartilage 2010;18:476-99.

44 Calderón-Larrañaga A, Abad-Díez JM, Gimeno-Feliu LA, et al. Global health care use by patients with type-2 diabetes: does the type of comorbidity matter? Eur J Intern Med 2015;26:203-10. 